\title{
Validation of revised methane and nitrous oxide profiles from MIPAS-ENVISAT
}

\author{
Johannes Plieninger ${ }^{1}$, Alexandra Laeng ${ }^{1}$, Stefan Lossow ${ }^{1}$, Thomas von Clarmann ${ }^{1}$, Gabriele P. Stiller ${ }^{1}$, \\ Sylvia Kellmann ${ }^{1}$, Andrea Linden ${ }^{1}$, Michael Kiefer ${ }^{1}$, Kaley A. Walker ${ }^{2}$, Stefan Noël ${ }^{3}$, Mark E. Hervig ${ }^{4}$, \\ Martin McHugh $^{5}$, Alyn Lambert ${ }^{6}$, Joachim Urban ${ }^{\mathrm{a},}$, James W. Elkins $^{7}$, and Donal Murtagh ${ }^{8}$ \\ ${ }^{1}$ Karlsruhe Institute of Technology, Institute for Meteorology and Climate Research, Karlsruhe, Germany \\ ${ }^{2}$ Department of Physics, University of Toronto, Toronto, Canada \\ ${ }^{3}$ Institut für Umweltphysik, University of Bremen, Bremen, Germany \\ ${ }^{4}$ GATS Inc, Driggs, Idaho, USA \\ ${ }^{5}$ Science and Technology Corporation, Hampton, VA, USA \\ ${ }^{6}$ Jet Propulsion Laboratory, California Institute of Technology, Pasadena, USA \\ ${ }^{7}$ NOAA Earth System Research Laboratory, Global Monitoring Division, Boulder, CO, USA \\ ${ }^{8}$ Department of Earth and Space Sciences, Chalmers University of Technology, Gothenburg, Sweden \\ ${ }^{a}$ formerly at: Department of Earth and Space Sciences, Chalmers University of Technology, Gothenburg, Sweden \\ $\dagger$ deceased
}

Correspondence to: Johannes Plieninger (johannes.plieninger@kit.edu)

Received: 3 November 2015 - Published in Atmos. Meas. Tech. Discuss.: 20 November 2015

Revised: 10 February 2016 - Accepted: 22 February 2016 - Published: 2 March 2016

\begin{abstract}
Improved versions of $\mathrm{CH}_{4}$ and $\mathrm{N}_{2} \mathrm{O}$ profiles derived at the Institute of Meteorology and Climate Research and Instituto de Astrofísica de Andalucía (CSIC) from spectra measured by the Michelson Interferometer for Passive Atmospheric Sounding (MIPAS) have become available. For the MIPAS full-resolution period (2002-2004) these are V5H_CH4_21 and V5H_N2O_21 and for the reducedresolution period (2005-2012) these are V5R_CH4_224, V5R_CH4_225, V5R_N2O_224 and V5R_N2O_225. Here, we compare $\mathrm{CH}_{4}$ profiles to those measured by the Fourier Transform Spectrometer on board of the Atmospheric Chemistry Experiment (ACE-FTS), the HALogen Occultation Experiment (HALOE) and the Scanning Imaging Absorption Spectrometer for Atmospheric CHartographY (SCIAMACHY), to the Global Cooperative Air Sampling Network (GCASN) surface data. We find the MIPAS $\mathrm{CH}_{4}$ profiles below $25 \mathrm{~km}$ to be typically higher of the order of $0.1 \mathrm{ppmv}$ for both measurement periods. $\mathrm{N}_{2} \mathrm{O}$ profiles are compared to those measured by ACE-FTS, the Microwave Limb Sounder on board of the Aura satellite (Aura-MLS) and the Submillimetre Radiometer on board of the Odin satellite (OdinSMR) as well as to the Halocarbons and other Atmospheric
\end{abstract}

Trace Species Group (HATS) surface data. The mixing ratios of the satellite instruments agree well with each other for the full-resolution period. For the reduced-resolution period, MIPAS produces similar values as Odin-SMR, but higher values than ACE-FTS and HATS. Below $27 \mathrm{~km}$, the MIPAS profiles show higher mixing ratios than Aura-MLS, and lower values between 27 and $41 \mathrm{~km}$. Cross-comparisons between the two MIPAS measurement periods show that they generally agree quite well, but, especially for $\mathrm{CH}_{4}$, the reduced-resolution period seems to produce slightly higher mixing ratios than the full-resolution data.

\section{Introduction}

The Michelson Interferometer for Passive Atmospheric Sounding (MIPAS; Fischer et al., 2008) measured limb emission spectra between 685 and $2410 \mathrm{~cm}^{-1}$. The instrument was a Fourier transform spectrometer run by the European Space Agency (ESA) on the Environmental Satellite (ENVISAT). It covers two measurement periods: from June 2002 to March 2004 it measured with a theoretical reso- 
lution of $0.025 \mathrm{~cm}^{-1}$ (after a "Norton-Beer Strong" apodisation, Norton and Beer, 1976, the spectral resolution is $0.0483 \mathrm{~cm}^{-1}$ ). This period is called full spectral resolution (FR). Between January 2005 and April 2012 it measured with a reduced spectral resolution ${ }^{1}$ (RR, theoretical resolution: $0.0625 \mathrm{~cm}^{-1}$, apodised resolution: $0.121 \mathrm{~cm}^{-1}$ ) but with a finer tangent altitude spacing. The tangent altitudes and their relative spacing depend on the measurement mode. Only spectra from the MIPAS nominal measurement mode have been used for this work. The limb scans have 17 tangent altitudes between 6 and $68 \mathrm{~km}$ for the full-resolution period and 27 spectra with tangent altitudes between 6 and $73 \mathrm{~km}$ in the reduced-resolution period.

Retrievals of temperature and its horizontal gradient, vertical pointing of the line of sight and many trace gases are conducted with the research data processor developed at the Institute of Meteorology and Climate Research in cooperation with Instituto de Astrofísica de Andalucía (CSIC) (von Clarmann et al., 2003). Earlier versions of the retrieval of $\mathrm{CH}_{4}$ and $\mathrm{N}_{2} \mathrm{O}$ with this processor for the full-resolution period were described by Glatthor et al. (2005), and for the reduced-resolution period by von Clarmann et al. (2009). The retrieval setup of the latest data versions V5R_CH4_224, V5R_CH4_225, V5R_N2O_224, V5R_N2O_225, V5H_CH4_21 and V5H_N2O_21 can be found in Plieninger et al. (2015). Data versions V5R_CH4_224 and V5R_CH4_225 are practically equivalent, each covering a different time period. The same holds for V5R_N2O_224 and V5R_N2O_225. The only technical difference between each two of these versions is that ECMWF analyses from a different source were used as a priori temperature profiles for the preceding retrieval of the temperature profiles which in turn were used for the retrieval of $\mathrm{CH}_{4}$ and $\mathrm{N}_{2} \mathrm{O}$. This has no noticeable effect on the data products of $\mathrm{CH}_{4}$ and $\mathrm{N}_{2} \mathrm{O}$. The only purpose of different version numbers is to guarantee full traceability and repeatability of the retrieval.

A Tikhonov first-order finite-differences constraint in combination with an all-zero a priori profile is used. This serves to smooth the retrieved profile, instead of pulling it towards the a priori profile itself (von Clarmann et al., 2009). For $\mathrm{CH}_{4}$ there are additional diagonal elements in the regularisation matrix for altitudes at $70 \mathrm{~km}$ and above (these are altitudes above the highest tangent altitude), where the profile is hence pulled towards zero.

The new retrieval setup versions rely on the usage of an updated spectroscopic data set, an improved handling of continuum contributions to the spectra, some smaller changes in the constraint, revised selections of microwindows and the additional jointly fitting of $\mathrm{HNO}_{3}$ and $\mathrm{H}_{2} \mathrm{O}$. The profiles are retrieved on a fixed-altitude grid between 0 and $120 \mathrm{~km}$. The grid spacing between 4 and $70 \mathrm{~km}$ is $1 \mathrm{~km}$, outside that range

\footnotetext{
${ }^{1}$ For this period, the term "optimised resolution" is used by ESA in their product names.
}

it is coarser. For the comparisons, only profile points have been used, where the diagonal element of the averaging kernel is above 0.03 and the visibility flag is 1 . The latter is a value which indicates for one profile point, whether the retrieval actually used measured data which was emitted at the altitude of this profile point. It is 0 if there are no spectra available either because the measured spectra in that altitude are influenced by emissions of clouds, or because there are no measurements available for that altitude. This is the case for all altitudes outside the MIPAS scan range, which is smaller than the range of the retrieval altitude grid. The resolution of the data products in the stratosphere ranges from 2.5 to $7 \mathrm{~km}$, (for details see Plieninger et al., 2015). The error profiles of the retrieved mixing ratios of $\mathrm{CH}_{4}$ and $\mathrm{N}_{2} \mathrm{O}$ resulting from instrument noise are reported for each measurement.

A comparison of MIPAS IMK/IAA $\mathrm{CH}_{4}$ to profiles measured by other instruments can be found in Laeng et al. (2015). They discuss data versions CH4_V5R_222 and CH4_V5R_223 which cover the MIPAS reduced-resolution period only. These versions are the direct predecessors of the CH4_V5R_224/CH4_V5R_225 versions under discussion in this work. The retrieval setup of versions CH4_V5R_222 and CH4_V5R_223 can be found in Plieninger et al. (2015). Laeng et al. (2015) found the MIPAS $\mathrm{CH}_{4}$ profiles below $20-25 \mathrm{~km}$ to be biased high and give $14 \%$ as the most likely value.

In this work we compare the new data versions V5R_CH4_224, V5R_CH4_225, V5R_N2O_224, V5R_N2O_225, V5H_CH4_21 and V5H_N2O_21 to various satellite instruments and additionally to surface data. These comparison instruments are described in Sect. 2. The documentation of the comparison method is given in Sect. 3, while Sect. 4 contains the validation itself. In Sect. 5 an attempt is made to gain some knowledge about how well the data products from the two different MIPAS measurement periods agree by using comparisons to other instruments. Section 6 gives a summary of our results. Since the bulk of the MIPAS data is from the reduced-resolution period, we discuss these profiles before those measured during the full-resolution period.

\section{Description of the comparison instruments}

\subsection{ACE-FTS}

The Atmospheric Chemistry Experiment Fourier Transform Spectrometer (ACE-FTS) on board SCISAT measures spectra between 750 and $4400 \mathrm{~cm}^{-1}$ in solar occultation mode (Bernath et al., 2005). A scan consists of several spectra measured with tangent heights from cloud top to $150 \mathrm{~km}$. From these spectra a retrieval of atmospheric temperature, pressure and abundances of various trace gases including $\mathrm{CH}_{4}$ and $\mathrm{N}_{2} \mathrm{O}$ is performed. The irregular retrieval grid is defined by the tangent altitudes. The retrieval setup is reported by 
Boone et al. (2005) for versions 2.1 and 2.2. For version 3.0 the changes in the retrieval setup are described in Boone et al. (2013) and chiefly address temperature issues. The $\mathrm{N}_{2} \mathrm{O}$ data used for the comparison shown here was version 3.5, which is nearly identical to version 3.0 , but solves a problem with the temperature and pressure a priori, affecting profiles measured after September 2010. For this version (and all latter versions), an altitude-dependent status flag is available (Sheese et al., 2015); for the comparison, we only use data where this flag is zero. Since the altitude flag is on an interpolated regular altitude grid, and we use the data on the retrieval grid, we assumed a data point on the retrieval grid to be valid, if both the flag at the grid point directly above and below were valid. The reported random errors are derived from the leastsquares fit and hence represent noise in the measured spectra. Additionally, they include a $\mathrm{CO}_{2}$ term depending on the relative difference between retrieved and a priori $\mathrm{CO}_{2}$ profile.

For $\mathrm{CH}_{4}$, a research version of the 3.5 retrieval was used. It is improved over version 3.5 in the treatment of the different isotopologues. The ACE-FTS profiles of the 3.5 research product have slightly lower mixing ratios than those of version 3.5. This difference is largest at $15 \mathrm{~km}$ and below, where it amounts to about 0.03 ppmv. The difference declines between 15 and $25 \mathrm{~km}$. Since MIPAS has higher mixing ratios, the differences between MIPAS and ACE-FTS as shown in this work are slightly larger than when MIPAS $\mathrm{CH}_{4}$ is compared to ACE-FTS version 3.5.

ACE-FTS is the only comparison instrument which covers profiles of both $\mathrm{CH}_{4}$ and $\mathrm{N}_{2} \mathrm{O}$ for both the MIPAS FR and RR measurement periods. The vertical resolution of the profiles are of the order of $4 \mathrm{~km}$. For the comparison to MIPAS profiles, data measured from 21 February 2004 on were used. The profiles for the comparison with the MIPAS fullresolution period all are measured between 60 and $90^{\circ} \mathrm{N}$. For the RR period, the profiles are distributed more evenly over the latitudes.

\subsection{SCIAMACHY}

The Scanning Imaging Absorption Spectrometer for Atmospheric CHartographY (SCIAMACHY; Bovensmann et al., 1999) is an UV/VIS/NIR/SWIR spectrometer on board of ENVISAT. The instrument measures in several different geometries. This comparison was made with $\mathrm{CH}_{4}$ profiles retrieved from the solar occultation mode. This mode provides one measurement per orbit, between 50 and $70^{\circ} \mathrm{N}$. The retrieval is conducted at the University of Bremen; the data version 4.5.2 has been used. The retrieval setup for these profiles is described by Noël et al. (2015). The valid data range for this product is $17-45 \mathrm{~km}$ and its vertical resolution is of the order of $4 \mathrm{~km}$. An error estimate based on the residual of the spectral fit is provided.

\subsection{HALOE}

From September 1991 to 21 November 2005, the HALogen Occultation Experiment (HALOE) on board of the Upper Atmosphere Research Satellite (UARS) measured profiles of $\mathrm{CH}_{4}$ in occultation geometry (Russell III et al., 1993). We compared MIPAS profiles to HALOE data version v19. This version has already been compared to ACE-FTS v2.2 profiles by De Mazière et al. (2008), where HALOE data were shown to have mixing ratios about 5-10\% lower than ACE-FTS. Waymark et al. (2013) found the $\mathrm{CH}_{4}$ ACE-FTS version 3.0 mixing ratios to be reduced at some altitudes compared to version 2.2. And since the version 3.5 research $\mathrm{CH}_{4}$ data have even lower mixing ratios than version 3.0, the difference between HALOE v19 and the latest ACE-FTS version (3.5 research) should be smaller than those in the earlier versions found by De Mazière et al. (2008). The typical vertical resolution of the profiles is given as $3-5 \mathrm{~km}$ (McHugh et al., 2005). An error estimate covering instrument noise is provided along with the data. The profiles used for the comparison to MIPAS data from the reduced-resolution period were measured from January to August 2005 and are distributed over all latitude bands. For the FR period the temporal overlap is larger and the collocated profiles are distributed over all latitudes and seasons.

\subsection{Aura-MLS}

Since July 2004, the Microwave Limb Sounder (MLS) on the Aura satellite measures $\mathrm{N}_{2} \mathrm{O}$ in the $640 \mathrm{GHz}$ region (Waters et al., 2006). Details for the retrieval version v2.2 can be found in Lambert et al. (2007). The vertical resolution is between 4 and $5 \mathrm{~km}$. The retrieval algorithm derives an error estimate based on the instrument noise.

For the comparison data version v3.3 was used. Here, for the temperature and tangent pressure the values retrieved in previous retrieval steps were used, while in version v2.2 (Lambert et al., 2007) those were retrieved jointly with $\mathrm{N}_{2} \mathrm{O}$. The following selection criteria were implemented (as suggested by Livesey et al., 2013): valid pressure range, 100$0.46 \mathrm{hPa}$, estimated precision is positive, the status flag is an even number, the quality field is larger than 1.4, the convergence field is below 1.01 and any profiles are discarded, where at $68 \mathrm{hPa}$ the $\mathrm{N}_{2} \mathrm{O}$ mixing ratio exceeds 350 ppbv. Since there is no data overlap with the MIPAS full-resolution period, comparisons could be made for the reduced-resolution data only.

\subsection{Odin-SMR}

The Sub-millimetre Radiometer (SMR, Murtagh et al., 2002) on board of the Odin satellite measures profiles of $\mathrm{N}_{2} \mathrm{O}$ in the $502.3 \mathrm{GHz}$ region. Measurements are available from February 2001 until the time of this writing, thus covering the complete temporal range of the MIPAS-ENVISAT data set. We 
use data from the Chalmers University of Technology product version v2.1. The retrieval uses an optimal estimation approach. Details can be found in Urban et al. (2005). The vertical resolution is of the order of $1.5 \mathrm{~km}$. The profiles cover an altitude of $15-70 \mathrm{~km}$. We only used data where the measurement response variable exceeded 0.9 and the quality flag is 0 or 4 . There is an error estimate available for the mapping of the instrument noise on the profile.

\subsection{GCASN surface data}

The Global Cooperative Air Sampling Network (GCASN) is a international project by the National Oceanic and Atmospheric Administration (NOAA) of the US Department of Commerce, operated by the Global Monitoring Division (GMD) at the Earth System Research Laboratory (ESRL). It measures amount of substance fractions of $\mathrm{CO}_{2}, \mathrm{CH}_{4}$ and several other trace gases. The surface air flask samples are taken at baseline observatories, additional fixed locations and ships and are analysed at measurement laboratories. Information on the $\mathrm{CH}_{4}$ product can be found in Dlugokencky et al. (1994) and Dlugokencky et al. (2005). For our comparisons we used $\mathrm{CH}_{4}$ mean data derived from 77 stations. These stations are located at latitudes between $89.98^{\circ} \mathrm{S}$ and $82.45^{\circ} \mathrm{N}$. The data version is 3 August 2015 (Dlugokencky et al., 2015).

\subsection{HATS surface data}

The Halocarbons and other Atmospheric Trace Species Group (HATS) of NOAA/GMD provide surface flask measurements of various atmospheric trace gases. We compared MIPAS $\mathrm{N}_{2} \mathrm{O}$ to the Combined Nitrous Oxide data product from the GMD at NOAA/ESRL (Hall et al., 2007; Elkins and Dutton, 2009). The measurements of 13 sites stationed at latitudes between $89.98^{\circ} \mathrm{S}$ and $82.45^{\circ} \mathrm{N}$ were used to calculate a global mean.

\section{Description of the comparison method}

To compare the various satellite instruments to MIPAS, the mean of several collocated pairs of profiles were taken. For the selection of the collocations, criteria of maximum spatial and temporal distance were applied. We used a maximum radius of $r_{\max }=500 \mathrm{~km}$ and a maximum temporal deviation of $\Delta t_{\max }=5 \mathrm{~h}$. For a comparison of MIPAS data with any of the instruments, the selection of matching pairs was unambiguous in a sense that only one profile complied with the candidate MIPAS profile and vice versa. The total number of matched pairs for each instrument and the temporal coverage of the matches are displayed in Table 1.

For the comparisons, the profiles of the instruments were interpolated to the MIPAS altitude grid. ACE-FTS, SCIAMACHY, HALOE and Odin-SMR provide the profiles on a geometric grid and hence a linear interpolation was used.
Table 1. Number of collocations $n$ between the instruments and MIPAS and their temporal ranges.

\begin{tabular}{llrr}
\hline Instrument & $\begin{array}{l}\text { MIPAS comp. } \\
\text { product }\end{array}$ & Temporal range & $n$ \\
\hline ACE-FTS & $\mathrm{CH}_{4}$ full res. & Feb 2004-Mar 2004 & 253 \\
SCIAMACHY & $\mathrm{CH}_{4}$ full res. & Jul 2002-Mar 2004 & 1232 \\
HALOE & $\mathrm{CH}_{4}$ full res. & Jul 2002-Mar 2004 & 2306 \\
\hline ACE-FTS & $\mathrm{CH}_{4}$ red. res. & Jan 2005-Apr 2012 & 8301 \\
SCIAMACHY & $\mathrm{CH}_{4}$ red. res. & Jan 2005-Apr 2012 & 7440 \\
HALOE & $\mathrm{CH}_{4}$ red. res. & Jan 2005-Aug 2005 & 157 \\
\hline ACE-FTS & $\mathrm{N}_{2} \mathrm{O}$ full res. & Feb 2004-Mar 2004 & 253 \\
Odin-SMR & $\mathrm{N}_{2} \mathrm{O}$ full res. & Jul 2002-Mar 2004 & 38739 \\
\hline ACE-FTS & $\mathrm{N}_{2} \mathrm{O}$ red. res. & Jan 2005-Apr 2012 & 8307 \\
Odin-SMR & $\mathrm{N}_{2} \mathrm{O}$ red. res. & Jan 2005-Mar 2012 & 174198 \\
Aura-MLS & $\mathrm{N}_{2} \mathrm{O}$ red. res. & Jan 2005-Apr 2012 & 830575 \\
\hline
\end{tabular}

For Aura-MLS the vertical coordinate of the profiles is pressure. These profiles were interpolated linearly in the $\log$ (pressure) domain to the MIPAS grid using the MIPAS pressures.

To avoid sampling problems due to the different vertical extent of the profiles, only data were used to calculate the mean profiles where both instruments in the respective pair provide valid values. The number of data points from which the mean is calculated is hence a function of the altitude. Typically the lower parts of the mean profiles contain fewer data points than the means at higher altitudes. This is due to the fact that MIPAS spectra containing a cloud signal beyond a certain threshold are excluded from the analysis. We discarded mean profile points which were calculated from less than 10 individual profile points to get meaningful statistics.

To compare two instruments, the mean over the data was calculated for each instrument. Additionally, the standard deviation for each instrument was determined to check whether atmospheric variations are reproduced by both instruments consistently. To examine the bias between the instruments, the difference (both absolute and relative) of the mean profiles was calculated. Also the standard error for the mean (absolute) difference has been derived to estimate the significance of the bias (von Clarmann, 2006).

For all the instruments, some kind of estimated error was available, representing statistical uncertainties (for details on these see Sect. 2). For MIPAS, this error estimate covers the influence of the instrument noise on the profiles. The combined error $\sigma_{\text {combined }}$ for two instruments

$\sigma_{\text {combined }}=\sqrt{\sigma_{\text {ref }}^{2}+\sigma_{\text {mip }}^{2}}$

could be derived from the given error estimates ( $\sigma_{\text {ref }}$ and $\sigma_{\text {mip }}$ ) with Eq. (1) and compared to the standard deviation of the difference. Since for the difference of collocated measurements, atmospheric variability should largely cancel out, the standard deviation of the difference describes the statisti- 
cal uncertainty of the difference. If the error estimates were perfect, and the instruments sampled exactly the same air mass, the combined error estimate should equal the standard deviation of the difference.

For MIPAS, there also is an extended error estimate available for some selected measurements. It includes propagated errors of the preceding fitted variables temperature and ozone mixing ratio as well as estimates of the uncertainties of the line of sight, the spectral shift, the calibration and the instrument line shape, the zonal temperature gradient, and the mixing ratios of all other gases where climatological values were used for the radiative transfer calculations during the retrieval. These estimated errors have been added quadratically to the MIPAS instrument noise error. A combination of this extended MIPAS error and the other instrument's error is shown as well. These extended error estimates are not mean values over the sample, but just a representative example of a typical error budget for one sample scan. Hence perfect agreement to the standard deviation of the difference cannot be expected.

In general, the vertical resolutions of MIPAS and the different instruments do not differ very much, hence one could assume that the MIPAS averaging kernels would not be needed to be applied. However, the MIPAS profiles' resolution is poorest at the boundaries, and the profiles of $\mathrm{CH}_{4}$ and $\mathrm{N}_{2} \mathrm{O}$ show large variations in the gradients at the lower boundaries. This could lead to comparison artefacts at the lower boundaries of the profiles. Since the lower part of the MIPAS profiles is of particular interest for this study because previous versions of $\mathrm{CH}_{4}$ and $\mathrm{N}_{2} \mathrm{O}$ from MIPAS show the largest bias in that altitude region, we decided to apply the MIPAS averaging kernels to the other instruments.

In the case of ACE-FTS the original profiles were degraded with the MIPAS averaging kernels (AKs) to remove artefacts in the differences, caused by their better altitude resolution. We used profiles $\boldsymbol{v} \boldsymbol{m} \boldsymbol{r}_{\mathrm{ACE}_{\text {native }}}$ on the native ACEFTS retrieval grid which consists of the tangent altitudes and hence is variable from profile to profile. This grid is coarser than the MIPAS grid. To apply the MIPAS AK ( $\left.\mathbf{A}_{\text {MIP }}\right)$, we interpolated the ACE profiles using the interpolation matrix $\mathbf{W}$ from the native ACE grid to the MIPAS grid. To obtain the degraded ACE profile on its own grid and to remove any finer structures which might be introduced by the using of the finer gridded MIPAS AK, we further applied the matrix which resamples from the fine to the coarse grid $\mathbf{V}=\left(\mathbf{W}^{\mathrm{T}} \mathbf{W}\right)^{-1} \mathbf{W}^{\mathrm{T}}$ to the result. A final interpolation to the MIPAS grid (using W) enables the calculation of the mean and taking the difference to the MIPAS profile. Since the MIPAS retrieval uses an a priori which is set equal to zero (Plieninger et al., 2015), the comparison profile of ACE-FTS degraded with the MIPAS AK is given by

$\boldsymbol{v} \boldsymbol{m} \boldsymbol{r}_{\mathrm{ACE}_{\mathrm{AK}}}=\mathbf{W V A}_{\mathrm{MIP}} \mathbf{W} \boldsymbol{v} \boldsymbol{m} \boldsymbol{r}_{\mathrm{ACE}_{\text {native }}}$.
The AK degraded value at one altitude $z_{i}$ is

$\boldsymbol{v} \boldsymbol{m} \boldsymbol{r}_{\mathrm{ACE}_{\mathrm{AK}} i}=\sum_{j} a_{i j} \boldsymbol{v} \boldsymbol{m} \boldsymbol{r}_{\mathrm{ACE}_{\mathrm{native}} j}$,

where $a_{i j}$ are the matrix elements of $\mathbf{W V A} \mathbf{A}_{\mathrm{MIP}} \mathbf{W}$.

The AK can only be applied to a profile point at an altitude $z_{i}$ if a valid data point of the reference instrument

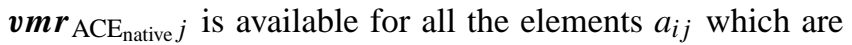
not zero. Since the AKs in reality are never exactly zero, we only discarded profile points, if the absolute of at least one AK element where no valid reference profile point is available is larger than a threshold of 0.01 . That means if for the calculation of the degraded mixing ratio at $z_{i}$, profile ele-

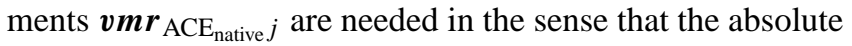
of $a_{i j}$ is above this threshold, and there is at least at one of those profile elements no valid data point of the reference instrument, then the calculation of this profile point is not carried out and the mixing ratio at $z_{i}$ is marked as missing instead. However, if there are valid data points of the reference instruments, then the elements where the absolute of $a_{i j}$ are below the threshold of course are not excluded from the calculation.

Due to this approach, the vertical extent of the profile is reduced after the degradation with the MIPAS AK. However, for ACE-FTS this alters the number of valid data points in the mean profiles only slightly because the vertical extent is larger than for MIPAS and only data points where both instruments show valid data are used to calculate the mean profiles. The ACE-FTS mixing ratios of $\mathrm{CH}_{4}$ did not change noticeably due to the degradation with the MIPAS AKs. The same holds for $\mathrm{N}_{2} \mathrm{O}$ in the full-resolution period. But for $\mathrm{N}_{2} \mathrm{O}$ in the reduced-resolution period, the profiles show much lower mixing ratios at the lower end after the degradation. Those differences amount to about $17 \mathrm{ppbv}$ at $9 \mathrm{~km}$ and decrease with altitude up to $18 \mathrm{~km}$, where both the degraded and the original ACE-FTS profiles show the same mixing ratios. This makes the application of the MIPAS AKs for $\mathrm{N}_{2} \mathrm{O}$ in the reduced-resolution period essential for the bias estimates. This is due to the MIPAS AKs being asymmetric at the lower end of the profile. Most of the information for the profile points at $12 \mathrm{~km}$ and below is in fact derived from spectra from altitudes above.

For Odin-SMR and Aura-MLS we used the same approach, since these are available on coarser grids than MIPAS as well. For both instruments the data loss due to the border effects of the application of the MIPAS AKs is more pronounced than for ACE-FTS, but still quite small: on average, about $3 \mathrm{~km}$ of the lower and upper ends of the profiles are lost. For Odin-SMR the extent of the mean profile is not altered, but the profile values below 22 and above $50 \mathrm{~km}$ are based on fewer data points. For Aura-MLS the upper end of the mean profile is reduced from 59 to $54 \mathrm{~km}$. At the lower end, the extent of the mean profile is not altered, but the mean below $21 \mathrm{~km}$ is based on fewer data points. Both instruments show slightly different mixing ratio differences to MIPAS 
at the lower profile ends after the application of the AKs. For Odin-SMR, the largest differences between original and degraded profiles for the reduced-resolution period occur at around $18 \mathrm{~km}$ and amount to around $8 \mathrm{ppbv}$, declining both below and above until $20 \mathrm{~km}$ where both profiles show the same mixing ratios. For the full-resolution period the differences between the two Odin-SMR profiles are similar, but their maximum is at $16 \mathrm{~km}$. For Aura-MLS the differences are almost $60 \mathrm{ppbv}$ at $14 \mathrm{~km}$ but decline quickly with altitude up to $16 \mathrm{~km}$ where the two Aura-MLS profiles show almost the same values. Between 17 and $19 \mathrm{~km}$ the differences amount to about 5 ppbv, above the degraded and the original profiles agree.

The HALOE profiles are given on a finer grid than MIPAS. $\mathbf{W}^{\prime}$ is the interpolation matrix from coarse grid (MIPAS) to fine grid (HALOE). Then the HALOE profiles degraded with the MIPAS averaging kernels are given by

$\boldsymbol{v} \boldsymbol{m} \boldsymbol{r}_{\mathrm{HALOE}_{\mathrm{AK}}}=\mathbf{A}_{\mathrm{MIP}} \mathbf{V}^{\prime} \boldsymbol{v} \boldsymbol{m} \boldsymbol{r}_{\mathrm{HALOE}_{\text {native }}}$,

where $\mathbf{V}^{\prime}=\left(\mathbf{W}^{\prime \mathrm{T}} \mathbf{W}^{\prime}\right)^{-1} \mathbf{W}^{\prime \mathrm{T}}$. The degraded profiles do not differ much from the original profiles. For the full-resolution period the differences are around 0.03 ppmv between 12 and $17 \mathrm{~km}$ and for the reduced-resolution period up to $0.08 \mathrm{ppmv}$ between 14 and $16 \mathrm{~km}$, with no differences outside these altitude ranges. By application of the averaging kernels, the altitude coverage of HALOE profiles on average is reduced by $4 \mathrm{~km}$. However, the total extent of the mean profile does not alter, there just are fewer data points in the lower-most $7 \mathrm{~km}$.

The SCIAMACHY profiles are given on the same grid as MIPAS. Hence no interpolation is needed for the application of the MIPAS AKs to SCIAMACHY profiles. However, due to the limited altitude range of SCIAMACHY profiles, few data points remain after the application of the AKs. The only difference between the original SCIAMACHY mean profile and the profile where the MIPAS AKs have been applied is a slight oscillation with an amplitude of about $0.06 \mathrm{ppmv}$ at the lower end (18-21 km in the comparison for the fullresolution period. Since the mean profile in that altitude region relies on very few data points, we think it is not representative. For the reduced-resolution period, the difference between profiles where the MIPAS AKs were applied and where not, is very small $(0.02 \mathrm{ppmv}$ at $17 \mathrm{~km}$, declining to zero at $20 \mathrm{~km}$ and $0.04 \mathrm{ppmv}$ at $43 \mathrm{~km}$, else zero). Because of the few data points left after the application of the AKs, we prefer to show the profiles without the MIPAS AKs.

To enable comparisons with data obtained by a totally independent measurement principle from the satellite instruments we also compared MIPAS measurements to data measured at the Earth surface. Their high precision $\left(\mathrm{CH}_{4}\right.$ : 1.5 ppbv precision Dlugokencky et al., 2009; $\mathrm{N}_{2} \mathrm{O}: 0.2 \mathrm{ppbv}$ precision Hall et al., 2007) compared to the various satellite instruments, makes them a valuable reference. MIPAS does not measure trace gas volume mixing ratios at the surface, which makes a direct comparison to surface data difficult. We assumed that the relatively long lifetime of $\mathrm{CH}_{4}$ and $\mathrm{N}_{2} \mathrm{O}$ in the atmosphere in combination with the well-mixed troposphere and the absence of sources of $\mathrm{CH}_{4}$ and $\mathrm{N}_{2} \mathrm{O}$ in the free troposphere allow the comparisons of MIPAS mixing ratios in the (upper) troposphere to surface values.

The comparison with the surface data networks GCASN $\left(\mathrm{CH}_{4}\right)$ and HATS $\left(\mathrm{N}_{2} \mathrm{O}\right)$ was done using global monthly means. For the surface data, monthly means $\overline{\boldsymbol{v m r}}_{i}$ for each individual station were used. Then an area-weighted global average $\overline{v m r}_{\text {global }}$ was taken for each month according to

$\overline{v m r}_{\text {global }}=\frac{\sum_{i} \cos \left(\boldsymbol{\varphi}_{i}\right) \overline{\boldsymbol{v m r}}_{i}}{\sum_{i} \cos \left(\boldsymbol{\varphi}_{i}\right)}$,

where $\varphi_{i}$ is the latitude.

For the comparison to surface data, we used the MIPAS mixing ratio at the altitude grid point $3 \mathrm{~km}$ below the tropopause to make sure to have a tropospheric value. For the determination of the tropopause from the MIPAS temperature profiles, we used two different approaches. In the latitude band between $25^{\circ} \mathrm{S}$ and $25^{\circ} \mathrm{N}$ we used the altitude where the potential temperature $\Theta$ equals $380 \mathrm{~K}$. Outside that latitude band, we used the WMO criterion (World Meteorological Organization, WMO). In some cases this approach failed, possibly because the resolution of the MIPAS temperature profiles (including a priori information) is too coarse, so a manual post-selection has been applied. A total of $1 \%$ of the profiles have been discarded from this analysis, most of them measured during Arctic winter conditions. The remaining MIPAS data were used to calculate monthly means for latitude bands $10^{\circ}$ wide. For each station of the comparison surface data network, the derived MIPAS value in the corresponding latitude band was taken to calculate a global monthly mean mixing ratio, using the same latitudedependent weighting function (Eq. 5) as for the surface data.

Possible errors of our method are that the value measured by MIPAS $3 \mathrm{~km}$ below the tropopause could still be influenced by stratospheric values; and that the tropospheric profile could not be sufficiently constant. Considering that there are no atmospheric sources for $\mathrm{CH}_{4}$ or $\mathrm{N}_{2} \mathrm{O}$, the latter would mean that the actual concentrations in the upper troposphere should be lower than the surface values. Both errors would essentially lead to an overestimation of the satellite concentration. So even if we cannot expect a perfect agreement between the tropospheric MIPAS value and the surface concentration, we would expect the satellite measurement to be roughly lower than the surface values. 

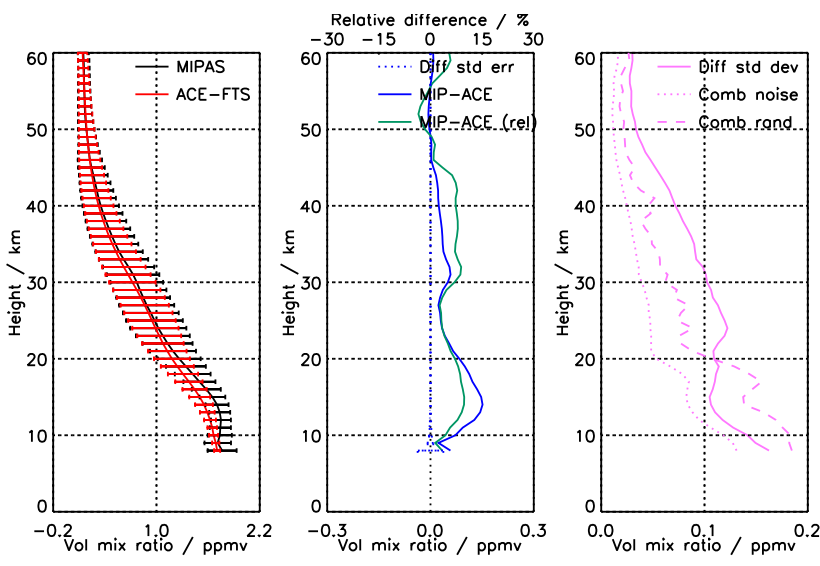

Figure 1. Comparison of $\mathrm{CH}_{4}$ from ACE-FTS and MIPAS reduced resolution (V5R_CH4_225 and V5R_CH4_224). Left panel: mean profiles of MIPAS (black) and its standard deviation (horizontal bars) and of ACE-FTS (red) and its standard deviation (horizontal bars). Middle panel: mean difference MIPAS minus ACE-FTS (blue solid), standard error of the difference (blue dotted), mean relative difference MIPAS minus ACE-FTS relative to ACE-FTS (green, upper axis). Right panel: combined mean estimated statistical error of the difference (pink dotted, contains MIPAS instrument noise error only), combined mean estimated statistical error of the difference (pink dashed, contains MIPAS example random error budget), standard deviation of the difference (pink solid).

\section{Validation}

\subsection{Validation of reduced-resolution methane}

In Fig. 1 mean profiles of $\mathrm{CH}_{4}$ both of MIPAS for the reduced-resolution period and ACE-FTS are shown. The profiles of the two instruments agree quite well with respect to their shape and values. ACE-FTS shows a steady decline of mixing ratio with altitude over the entire profile. Above $12 \mathrm{~km}$, this is the case for MIPAS as well. Between 9 and $12 \mathrm{~km}$ MIPAS shows a slight increase with altitude. Above around $13-14 \mathrm{~km}$ a strong negative vertical gradient is observed by both instruments, which becomes less pronounced above approximately $40 \mathrm{~km}$. Between 15 and $46 \mathrm{~km}$ the MIPAS profile shows slightly higher values than ACE-FTS. Above that altitude the profiles agree well.

The standard deviation of the profiles is mostly similar, but especially in lower altitudes MIPAS shows a slightly higher variation. The general agreement of the two standard deviations serves as an additional indicator that the two instruments describe the same physical distribution.

The mean differences (middle panel) show that the MIPAS profiles have higher mixing ratios below $45 \mathrm{~km}$, with maximum differences of around $0.15 \mathrm{ppmv}$ at $13-15 \mathrm{~km}$. Between 47 and $56 \mathrm{~km}$ MIPAS has slightly lower mixing ratios than ACE-FTS, further above MIPAS values are higher again. The relative differences do not exceed $10 \%$. The standard error of the mean difference generally is very small, in-
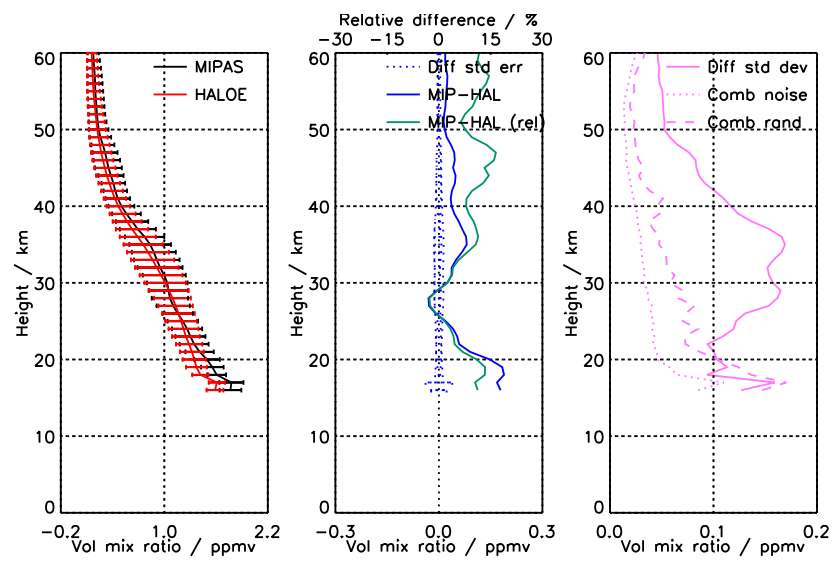

Figure 2. Comparison of $\mathrm{CH}_{4}$ from HALOE and MIPAS reduced resolution (V5R_CH4_225 and V5R_CH4_224). Details as in Fig. 1.

dicating that the bias between the two data sets is significant. Only the profile points between 8 and $9 \mathrm{~km}$ show areas where the bias is smaller than its uncertainty and hence is statistically insignificant.

The combined estimated error is smaller than the standard deviation of the difference almost over the entire profile, so one or both of the instruments underestimates its errors. This is not surprising, because the available error estimates do not cover the total random error, but only measurement noise. Any (random) parameter errors (e.g. from previously fitted profiles) are not accounted for. Including the MIPAS extended random error in the estimate (pink dashed curve in third panel of Fig. 1) leads to higher values, but above $20 \mathrm{~km}$, there remain unexplained discrepancies between errors estimated and standard deviations observed. Below $20 \mathrm{~km}$ the extended random errors seem to be overestimated.

In Fig. 2 the comparison of $\mathrm{CH}_{4}$ reduced-resolution data to the HALOE profiles is shown. Both mean profiles have small kinks at 17 and $18 \mathrm{~km}$, and a local maximum at $17 \mathrm{~km}$. Above they show a steady decrease with height over the entire altitude range. However, below $35 \mathrm{~km}$, the HALOE profile shows a smoother decline, while the MIPAS profile's vertical gradient has more oscillations, even though there are no actual local extrema. Above that altitude, the vertical gradients of the two profiles are almost identical. Over the entire profile, HALOE's mixing ratios are smaller than those of MIPAS. The bias is statistically significant everywhere. The maximum differences occur around $17 \mathrm{~km}$ and are around $0.2 \mathrm{ppmv}$. Above that altitude, they look quite similar to the differences between MIPAS and ACE-FTS. The differences have a minimum at $28 \mathrm{~km}$ and a secondary maximum at around $35 \mathrm{~km}$ of about $0.1 \mathrm{ppmv}$. In ACE-FTS such a secondary maximum in differences is present as well, however it is located in slightly lower altitudes at $31 \mathrm{~km}$ and the differences are smaller ( $0.05 \mathrm{ppmv})$. The combined error of both instruments is clearly underestimated above $20 \mathrm{~km}$, 

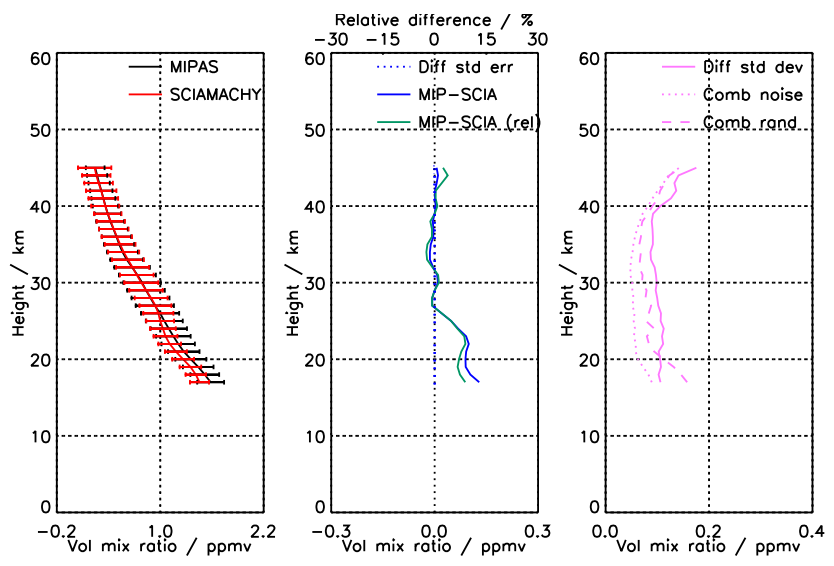

Figure 3. Comparison of $\mathrm{CH}_{4}$ from SCIAMACHY and MIPAS reduced resolution (V5R_CH4_225 and V5R_CH4_224). Details as in Fig. 1.

even taking the extended MIPAS error into account. Below that altitude the combined extended random error estimate is slightly larger than the standard deviation of the difference, while the error estimate with noise only for MIPAS is still below the standard deviation.

Figure 3 shows the mean profiles from SCIAMACHY compared to MIPAS. The profiles from both instruments show a steady decrease with altitude. However, while the SCIAMACHY profile declines much less between 25 and $27 \mathrm{~km}$, the MIPAS profile declines more smoothly. Between 17 and $25 \mathrm{~km}$, SCIAMACHY mixing ratios are about 0.15 ppmv lower. Then the differences decrease, above $27 \mathrm{~km}$ there are small differences with alternating signs but in general there is a good agreement between the instruments. Over the entire profile, the bias is significant. The combined error estimate is lower than the standard deviation of the difference for the estimate using the noise error only. With the extended MIPAS error budget, the combined error below $22 \mathrm{~km}$ is larger than the standard deviation, indicating again that the extended MIPAS error budget is probably overestimated. However, considering that the extended error budget is for an example measurement only, the agreement between the standard deviation of the difference and the estimated error seems to be reasonable.

The comparison of MIPAS with the GCASN surface data is shown in Fig. 4.

MIPAS mixing ratios are higher than those of GCASN, the differences average to 0.05 ppmv. While the GCASN data show a clear positive trend over the observation period, which is well documented (e.g. Dlugokencky et al., 2009) for MIPAS data this does not seem to be the case. This could be due to a negative drift overlaid on MIPAS $\mathrm{CH}_{4}$ measurements. This would be in agreement with recent findings by Kiefer et al. (2013) and Eckert et al. (2014) who found that MIPAS measurements are prone to an instrument drift due to changing detector nonlinearities. The analysis of Kiefer

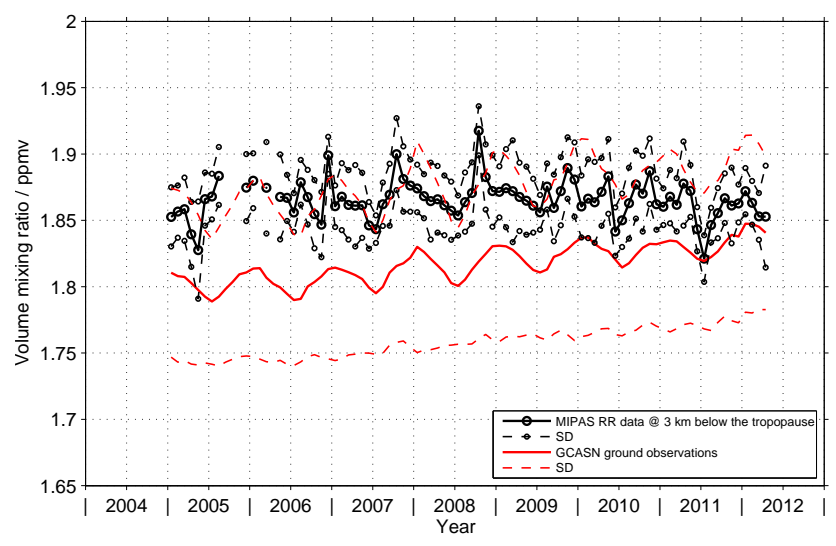

Figure 4. Comparison between volume mixing ratios of $\mathrm{CH}_{4}$ from GCASN and MIPAS reduced resolution (V5R_CH4_225 and V5R_CH4_224). Large black circles/continuous line: monthly mean mixing ratios for MIPAS, small black circles/dashed line: standard deviation for MIPAS; red continuous line: monthly mean mixing ratios for GCASN; red dashed line: standard deviation for GCASN.

et al. (2013) proves the resulting drift due to changing detector nonlinearities to be negative in most latitudes for $\mathrm{CH}_{4}$ in the upper troposphere and lower stratosphere. It is of the order of $0.04 \mathrm{ppmv} \mathrm{dec}^{-1}$.

The comparisons of MIPAS reduced-resolution $\mathrm{CH}_{4}$ profiles to the three satellite instruments are not conclusive. Between 30 and $35 \mathrm{~km}$ HALOE and ACE-FTS show lower mixing ratios than MIPAS, while SCIAMACHY is slightly higher. The latter instrument has comparatively low values at $25 \mathrm{~km}$, where the agreement between ACE-FTS and HALOE to MIPAS is quite good. Below $25 \mathrm{~km}$ the comparisons to ACE-FTS, HALOE and SCIAMACHY show that MIPAS has the highest mixing ratios. Hence a positive bias in that altitude region is likely. It is largest below $20 \mathrm{~km}$ where it is between 0.1 and $0.2 \mathrm{ppmv}$. This bias is qualitatively confirmed by the comparison with the GCASN surface data, however here the difference is only $0.05 \mathrm{ppmv}$. The largest difference occurs with HALOE at $17 \mathrm{~km}$, where MIPAS mixing ratios are around 0.2 ppmv higher. Overall versions V5R_CH4_224 and V5R_CH4_225 have improved significantly compared to versions V5R_CH4_222 and V5R_CH4_223 where Laeng et al. (2015) found differences to HALOE of up to 0.35, and 0.2 ppmv to ACE-FTS (version 3.5) and SCIAMACHY in the lower part of the profile. Considering that the ACE-FTS version 3.5 used in the comparison of Laeng et al. (2015) provides higher values than the 3.5 research version used here (about 0.03 ppmv at those altitudes), the reduction of the values in the newer MIPAS version is of the order of 0.08 to 0.15 ppmv.

All the comparisons show the combined random error estimate to be larger than the standard deviation of the difference in the lower altitudes. This could indicate that the selected MIPAS example measurement, for which the extended ran- 

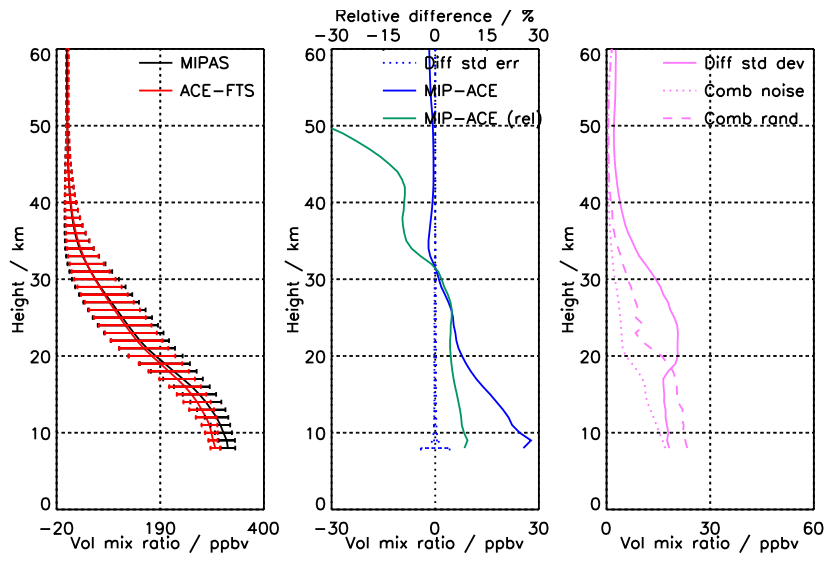

Figure 5. Comparison of $\mathrm{N}_{2} \mathrm{O}$ from ACE-FTS and MIPAS reduced resolution (V5R_N2O_224 and V5R_N2O_225). Details as in Fig. 1.
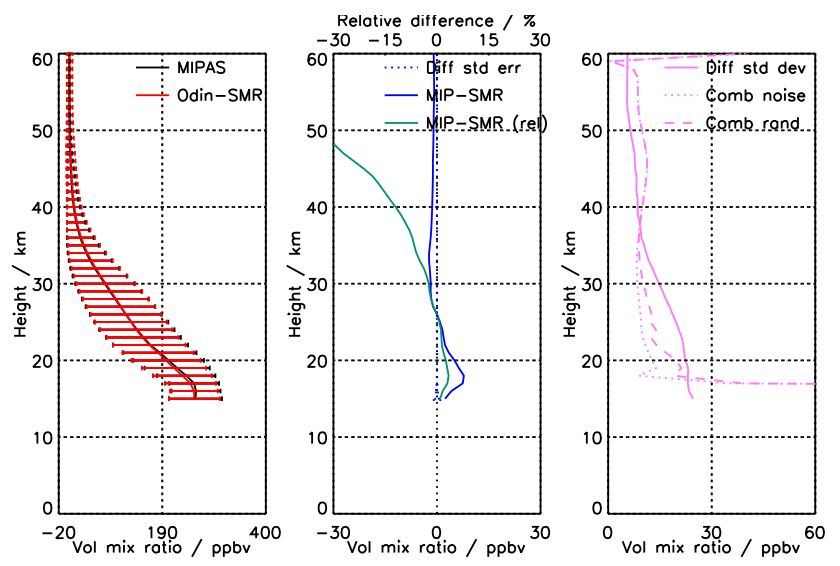

Figure 6. Comparison of $\mathrm{N}_{2} \mathrm{O}$ from Odin-SMR and MIPAS reduced resolution (V5R_N2O_224 and V5R_N2O_225). Details as in Fig. 1.

dom error estimate was conducted, is less representative for the entire data set than hoped for. At higher altitudes, however, the combined error estimate is smaller than the standard deviation of the difference.

\subsection{Validation of reduced-resolution nitrous oxide}

The comparison for the MIPAS reduced-resolution period $\mathrm{N}_{2} \mathrm{O}$ profiles to ACE-FTS is shown in Fig. 5. Both profiles show a steady, smooth decrease with altitude. Below $30 \mathrm{~km}$ the profiles from ACE-FTS have lower mixing ratios than MIPAS. The largest differences between the two instruments occur at $10 \mathrm{~km}$ and are around $30 \mathrm{ppbv}$. The differences decline with altitude until around $33 \mathrm{~km}$, where MIPAS has slightly lower mixing ratios. In general the agreement between the two instruments above $30 \mathrm{~km}$ is good.

In Fig. 6 the MIPAS $\mathrm{N}_{2} \mathrm{O}$ profiles are compared to those measured by Odin-SMR. The agreement between the two in-
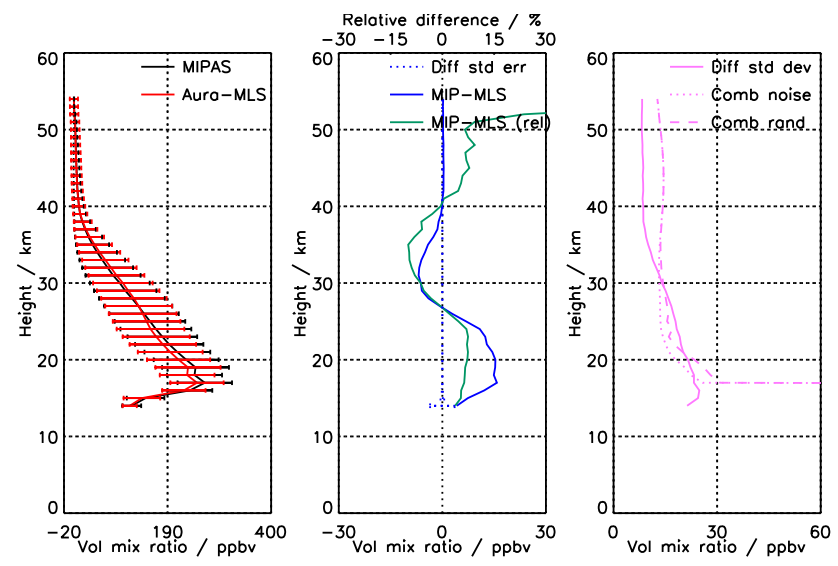

Figure 7. Comparison of $\mathrm{N}_{2} \mathrm{O}$ from Aura-MLS and MIPAS reduced resolution (V5R_N2O_224 and V5R_N2O_225). Details as in Fig. 1.

struments is good. Their shapes are identical. Below $25 \mathrm{~km}$ MIPAS is slightly higher. The differences are largest at 17$18 \mathrm{~km}$ and are just below $10 \mathrm{ppbv}$. Above $25 \mathrm{~km}$ MIPAS has slightly lower mixing ratios than Odin-SMR. In the upper part of the profile, the relative differences are quite high, with MIPAS showing lower values. But since this occurs at altitudes where the absolute volume mixing ratios are very low, this does not indicate any severe problems with the data sets. The combined errors of the two instruments are underestimated below $36 \mathrm{~km}$, even with the extended MIPAS error budget (although it clearly is an improvement over the simple noise-only variant). Above, the estimated errors are larger than the standard deviation and hence probably overestimated, but in general the agreement is good. At the regions below 17 and above $58 \mathrm{~km}$ the combined errors are very large.

The comparison of MIPAS profiles to Aura-MLS (Fig. 7) demonstrates that the two instruments generally agree with respect of the shape of the profile. The profiles show a maximum at $17 \mathrm{~km}$ and an almost steady decrease above that only between 18 and $19 \mathrm{~km}$ are the mixing ratios of both instruments slightly increasing. Below $17 \mathrm{~km}$, the profiles show declining values towards lower altitudes. MIPAS measured higher mixing ratios between 15 and $27 \mathrm{~km}$ and slightly lower values between 27 and $41 \mathrm{~km}$. The differences are largest at $17-21 \mathrm{~km}$ and amount to approximately $17 \mathrm{ppbv}$.

The maximum in the mean profile is caused by the altitude-dependent sampling. Those profiles which have values at lower altitudes are typically measured outside the Tropics and measure lower mixing ratios than those which measure in tropical regions. A mean based on entire profiles (within a fixed altitude range) does not show this maximum, but either the vertical extension or the amount of measurements in the mean is diminished, depending on the chosen altitude range. The combined error estimate is too low between about $19 \mathrm{~km}$ and too high above $31 \mathrm{~km}$. Outside that 


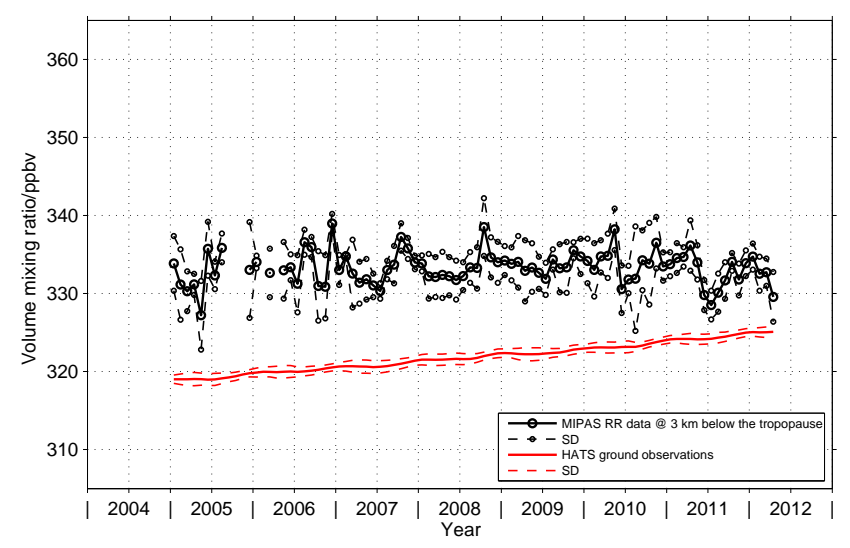

Figure 8. Comparison between volume mixing ratios of $\mathrm{N}_{2} \mathrm{O}$ from HATS and MIPAS reduced resolution (V5R_N2O_224 and V5R_N2O_225). Details as in Fig. 4.

altitude range, the error estimates are larger than what would be expected by the standard deviation. This is true, as much for the estimate without as for that with the extended error budget. The latter decreases the difference to the standard deviation of the difference, especially in the lower part of the profile, hence a reasonably good agreement can be achieved.

Figure 8 shows the comparison of global monthly means of MIPAS and HATS surface data.

On average, MIPAS data prove to be $12 \mathrm{ppbv}$ higher than the surface measurements. Similarly to the comparison for $\mathrm{CH}_{4}$, the trend over the period agrees poorly. As for $\mathrm{CH}_{4}$ the MIPAS trend is smaller than that for the surface data, possibly due to negative instrument drift, which would be in agreement to the findings of Kiefer et al. (2013) for $\mathrm{N}_{2} \mathrm{O}$ in the upper troposphere and lower stratosphere (around $\left.7 \mathrm{ppbv} \mathrm{dec}^{-1}\right)$.

While there are noticeable differences between MIPAS and ACE-FTS and Aura-MLS, the agreement with OdinSMR is better. MIPAS seems to have a tendency to have a high bias in the lower part of the profile and low bias in the upper part compared to the other instruments. But the latter is true only for the comparisons to ACE-FTS and Odin-SMR; compared to Aura-MLS the MIPAS mixing ratios are higher above $40 \mathrm{~km}$.

\subsection{Validation of full-resolution methane}

The comparison of ACE-FTS data to MIPAS $\mathrm{CH}_{4}$ profiles from the full-resolution period (Fig. 9) uses only data from the northern high latitudes, due to the short data overlap and its non-uniform monthly latitude sampling. Both profiles have a similar shape and show a steady decrease with altitude. Differences of up to $0.12 \mathrm{ppmv}$ at $17 \mathrm{~km}$ occur and in the lower part of the profile MIPAS has slightly higher mixing ratios than ACE-FTS. Above $19 \mathrm{~km}$ the agreement between the two instruments is excellent.
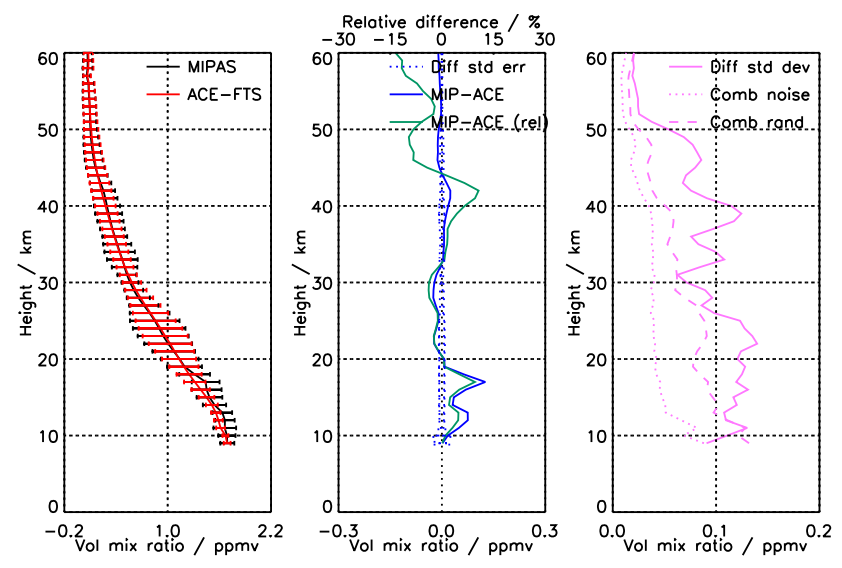

Figure 9. Comparison of $\mathrm{CH}_{4}$ from ACE-FTS and MIPAS full resolution (V5H_CH4_21). Details as in Fig. 1.
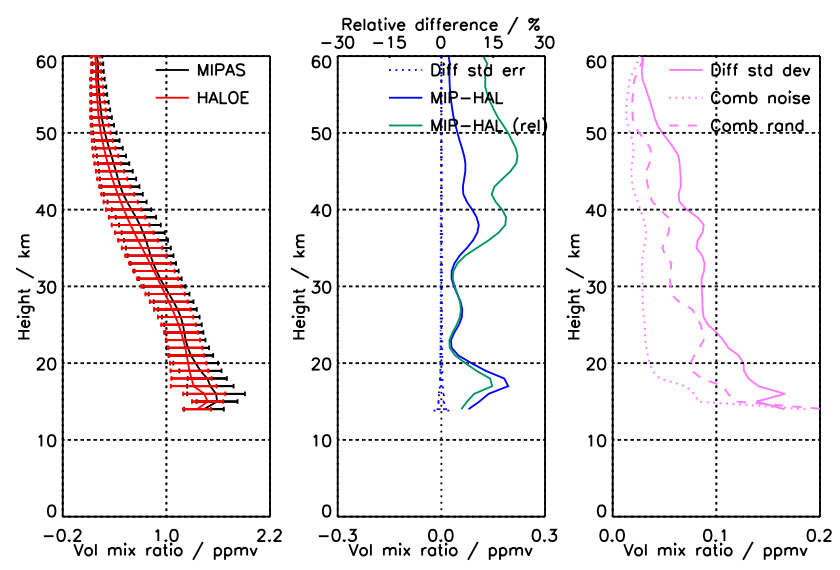

Figure 10. Comparison of $\mathrm{CH}_{4}$ from HALOE and MIPAS full resolution (V5H_CH4_21). Details as in Fig. 1.

As in the reduced-resolution period, the combined error estimate of the instruments using the MIPAS extended error budget is slightly too low, except for altitudes below $10 \mathrm{~km}$, where the random errors seem to be slightly overestimated. Using the MIPAS extended error budget improves the situation, but the resulting estimate still is lower than the standard deviation of the difference.

In Fig. 10 the MIPAS full-resolution $\mathrm{CH}_{4}$ product is compared to HALOE. Both the instruments measured a steady decline with altitude, but the HALOE profile is smoother than MIPAS, for which the vertical gradient shows more variation. Over almost the entire profile, MIPAS measures higher mixing ratios than HALOE. The largest differences occur below $20 \mathrm{~km}$; at its maximum MIPAS is about $0.2 \mathrm{ppmv}$ higher than HALOE.

The standard deviation of the difference indicates that the combined errors for the instruments are underestimated, even taking the extended MIPAS error budget into account.

The comparison of MIPAS full-resolution $\mathrm{CH}_{4}$ profiles to SCIAMACHY (Fig. 11) is very similar to that of the reduced- 

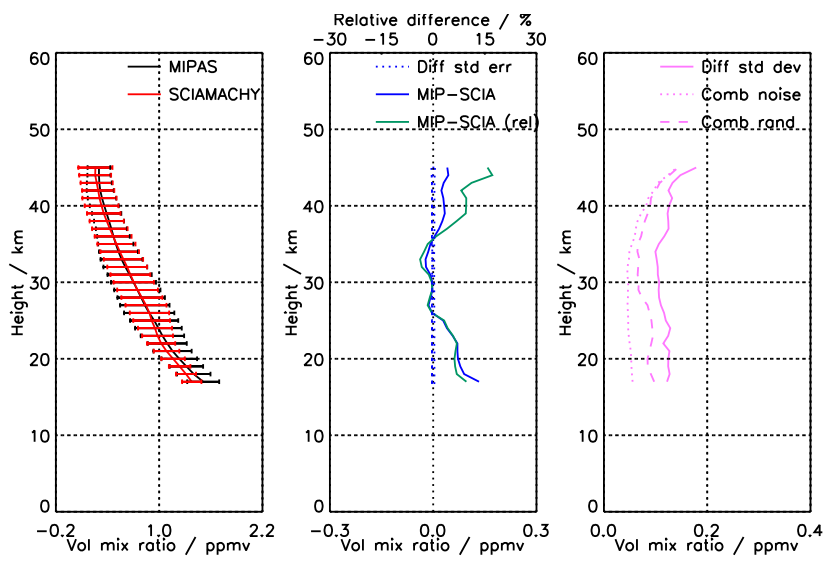

Figure 11. Comparison of $\mathrm{CH}_{4}$ from SCIAMACHY and MIPAS full resolution (V5H_CH4_21). Details as in Fig. 1 .

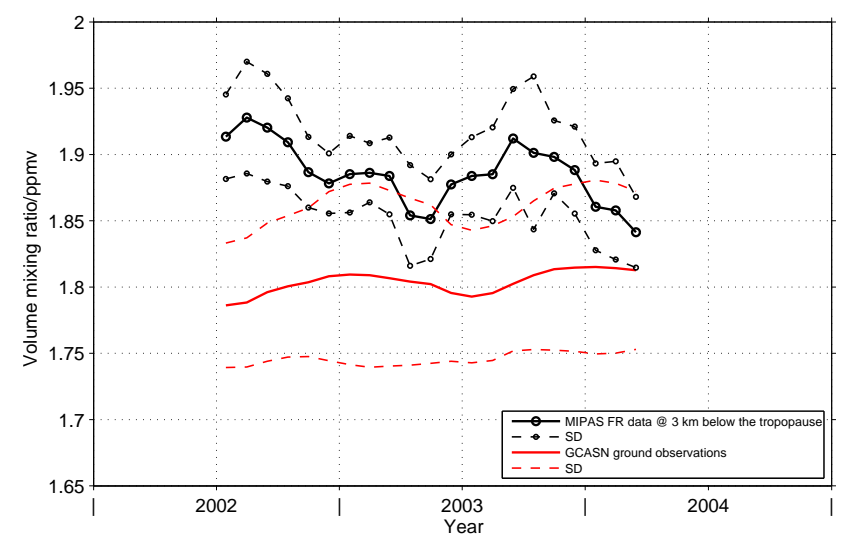

Figure 12. Comparison volume mixing ratios of $\mathrm{CH}_{4}$ from GCASN and MIPAS full resolution (V5H_CH4_21). Details as in Fig. 4.

resolution period. Below $25 \mathrm{~km}$ the MIPAS mixing ratios are higher; the differences are below 0.1 ppmv. Between 25 and $35 \mathrm{~km}$ the agreement is very good, MIPAS showing slightly lower mixing ratios. Above $35 \mathrm{~km}$ MIPAS has slightly higher mixing ratios than SCIAMACHY. The combined errors are slightly underestimated.

From comparisons of MIPAS global mean data to GCASN surface measurements (Fig. 12), we find that MIPAS measures mixing ratios that are on average $0.07 \mathrm{ppmv}$ higher than the surface data.

The comparisons with different instruments offer no easy conclusions. While the MIPAS profiles agree well with ACEFTS, they have higher mixing ratios than HALOE. They are higher than SCIAMACHY below $25 \mathrm{~km}$ and slightly lower above that altitude, yet higher again above $35 \mathrm{~km}$. However, at around $17 \mathrm{~km}$ the differences to ACE-FTS, HALOE and SCIAMACHY have their maximum, so it is likely that MIPAS has a high bias at this altitude. Between 25 and $35 \mathrm{~km}$ MIPAS agrees well with ACE-FTS and SCIAMACHY, and even while lower mixing ratios were measured by HALOE,
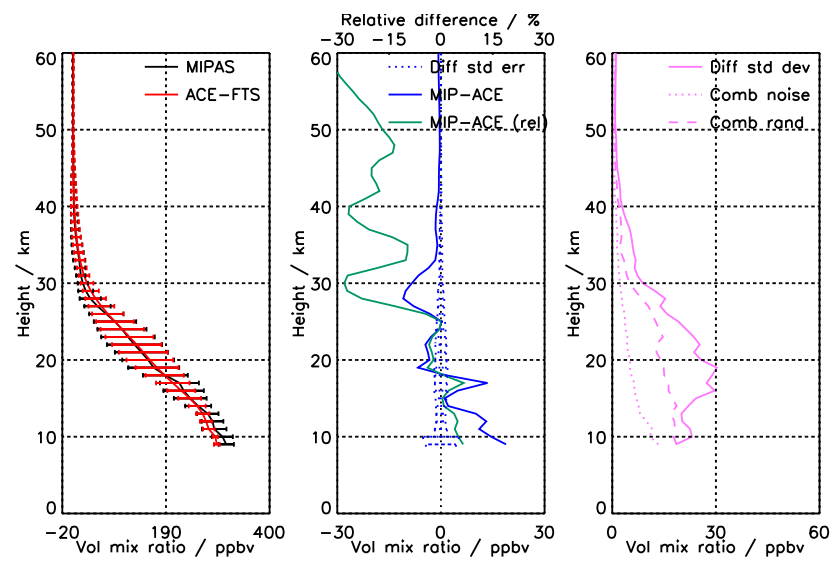

Figure 13. Comparison of $\mathrm{N}_{2} \mathrm{O}$ from ACE-FTS and MIPAS full resolution (V5H_N2O_21). Details as in Fig. 1.

the bias between MIPAS and HALOE is lower than at other altitudes.

\subsection{Validation of full-resolution nitrous oxide}

In Fig. 13 the MIPAS full-resolution $\mathrm{N}_{2} \mathrm{O}$ profiles are compared to those measured by ACE-FTS. While the general agreement between the instruments with respect to the shape of their profiles is good, the MIPAS profile below $20 \mathrm{~km}$ shows more bumps and kinks. The differences between the two profiles are of the order of $10 \mathrm{ppbv}$ and have alternating signs. Their maximum is at the lower end of the profiles and exceeds $15 \mathrm{ppbv}$. Below $18 \mathrm{~km}$ MIPAS provides mostly higher mixing ratios than ACE-FTS; above $18 \mathrm{~km}$ ACE-FTS is higher, especially between 25 and $32 \mathrm{~km}$. In between 18 and $25 \mathrm{~km}$ and above $32 \mathrm{~km}$ there is good agreement between the instruments. The bias is significant over the entire altitude range. The estimate of the combined error is lower than what would be expected from the standard deviation of the difference.

The comparison of MIPAS to profiles measured by OdinSMR generally looks good (Fig. 14). Below $19 \mathrm{~km}$ MIPAS is higher; the largest difference occurs at $16 \mathrm{~km}$ and is just below 15 ppbv. Between 19 and $35 \mathrm{~km}$ the agreement is almost perfect. Above that altitude the absolute differences remain very small, but MIPAS is slightly lower, which leads to notably relative differences. As for the reduced-resolution period, the combined error estimates are lower than the standard deviation of the difference in the lower part of the profile, and higher in the upper part.

Figure 15 shows the comparison of global monthly means from MIPAS to those from the HATS surface data for the full-resolution period. The MIPAS mixing ratios are $24 \mathrm{ppbv}$ higher.

Especially around $17 \mathrm{~km}$ MIPAS seems to measure $\mathrm{N}_{2} \mathrm{O}$ volume mixing ratios which are too high by $10-15$ ppbv. The differences to the two satellite instruments are smaller than 

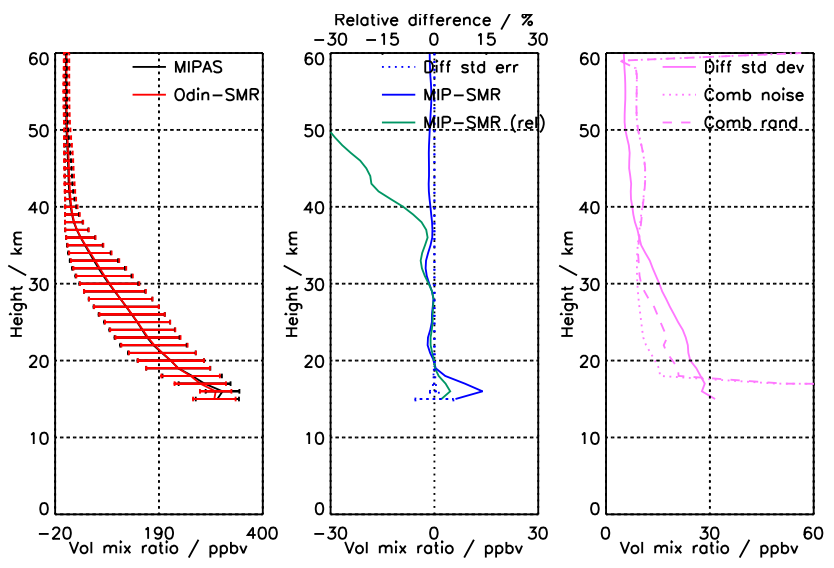

Figure 14. Comparison of $\mathrm{N}_{2} \mathrm{O}$ from Odin-SMR and MIPAS full resolution (V5H_N2O_21). Details as in Fig. 1.

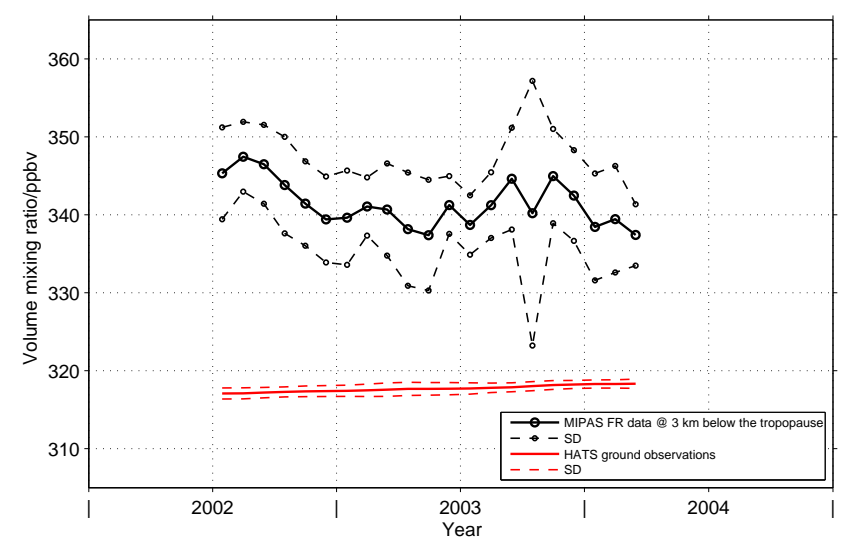

Figure 15. Comparison between volume mixing ratios of $\mathrm{N}_{2} \mathrm{O}$ from HATS and MIPAS full resolution (V5H_N2O_21). Details as in Fig. 4.

the difference to the surface data. At higher altitudes the comparisons are not conclusive. In general the absolute differences are small, but there are rather large relative differences where MIPAS $\mathrm{N}_{2} \mathrm{O}$ has lower mixing ratios than ACE-FTS and Odin-SMR.

\section{Comparison between full- and reduced-resolution period}

The comparisons in Sect. 4 have been done independently for the two MIPAS measurement periods. However, since some of the comparisons are available for both the MIPAS full- and reduced-resolution period, we can draw some conclusions about the consistency of the two data sets in doing cross-comparisons between the differences to other instruments for the two MIPAS measurement periods.
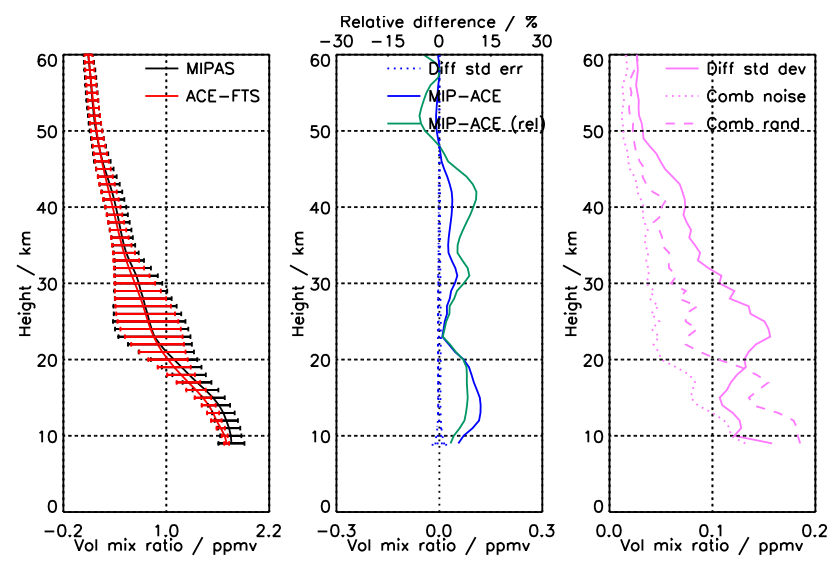

Figure 16. Comparison of $\mathrm{CH}_{4}$ from ACE-FTS and MIPAS reduced resolution (V5R_CH4_224 and V5R_CH4_225) at 60-90 N in February and March. Details as in Fig. 1.

\subsection{Consistency check for $\mathrm{CH}_{4}$}

For $\mathrm{CH}_{4}$ the three comparison instruments ACE-FTS, HALOE and SCIAMACHY all cover both MIPAS measurement periods. However for ACE-FTS, due to the small overlap between the two instruments, only data between $60-90^{\circ} \mathrm{N}$ in February and March are available. To avoid sampling artefacts, in Fig. 16 the V5R_CH4_224 and V5R_CH4_225 products in the same latitudinal range in February and March only are shown.

This enables a comparison with Fig. 9 without any effects resulting from seasonal or latitudinal sampling discrepancies. However, the data for the full-resolution period cover only measurements from 2004, while the reduced-resolution comparison uses data from 7 years (2006-2012), which makes this comparison vulnerable to meteorological anomalies, especially in 2004. The differences between MIPAS and ACEFTS for the two MIPAS measurement periods look similar. In general the differences of the MIPAS reduced-resolution comparison look smoother than for the full-resolution period. This is probably due to the different sample size. The MIPAS reduced-resolution data provide slightly higher differences to ACE-FTS almost over the entire profile. Only the spike at $17 \mathrm{~km}$ in the MIPAS full-resolution profile shows a similar difference as the reduced-resolution data, where no such spike is visible.

The comparison between HALOE and MIPAS fullresolution data covers all the seasons, while for the reducedresolution data only profiles from January to August 2005 were measured. Hence we also compared means of fullresolution data only using profiles in this seasonal range as well. However, the differences then reproduced the differences shown in Fig. 10. For this reason this extra comparison is not shown here. Comparison of the differences between HALOE and MIPAS for the two measurement periods (Figs. 2 and 10) reveals that over most of the profile, the 
MIPAS reduced-resolution data lead to slightly higher differences than the full-resolution data, while the shape of the differences is similar. In the full-resolution data however, at $17 \mathrm{~km}$ there are particularly high values in the MIPAS profile. This is similar to the spike in the same altitude at the comparison of the MIPAS full-resolution data with ACE-FTS.

The comparison of the differences between SCIAMACHY and the two MIPAS measurement periods (Figs. 3 and 11), shows that at the lower altitudes MIPAS produces slightly higher mixing ratios for the reduced-resolution period than for the full-resolution data. At altitudes above $35 \mathrm{~km}$, the fullresolution period seems to lead to higher mixing ratios than the reduced-resolution period.

In the comparisons of MIPAS with the GCASN surface data set (Figs. 4 and 12), the differences are very similar, the bias for the full resolution is slightly higher.

In conclusion, all the satellite comparisons suggest that the MIPAS reduced-resolution period shows slightly higher mixing ratios (about $0.05 \mathrm{ppmv}$ ) than the data for the fullresolution period, at least in the lower part of the profile. An exception seems to be the kink in MIPAS full-resolution data. Hence there could be some bias between the measurement periods. The surface data comparison, however, hints at a better agreement between the two MIPAS data sets in the troposphere than at the altitudes above.

\subsection{Consistency check for $\mathrm{N}_{2} \mathrm{O}$}

$\mathrm{N}_{2} \mathrm{O}$ profiles from ACE-FTS and Odin-SMR cover both the MIPAS measurement periods, hence we use those comparison to draw conclusions about the consistency of the two MIPAS data sets.

For reasons described in Sect. 5.1, for the crosscomparison using ACE-FTS, collocated profiles from February and March between 60 and $90^{\circ} \mathrm{N}$ have been used for $\mathrm{N}_{2} \mathrm{O}$ MIPAS reduced-resolution data (Fig. 17, for the fullresolution period, see Fig. 13). Below $20 \mathrm{~km}$, the MIPAS reduced-resolution data provides higher mixing ratios than the full-resolution data; the latter seem to agree better with the ACE-FTS instrument. Both differences to ACE-FTS have some oscillations, but they are not correlated.

The comparisons to Odin-SMR both look good (Figs. 14 and 6). For the full-resolution period there are small differences at $17 \mathrm{~km}$, where MIPAS shows slightly higher mixing ratios, while for the reduced-resolution period this is less pronounced. In 19-20 km however, MIPAS mixing ratios in the reduced-resolution period are slightly higher than OdinSMR, while for the full-resolution period the instruments agree well.

As for $\mathrm{CH}_{4}$ the difference between the HATS surface data and MIPAS for the full-resolution period (Fig. 15) is slightly larger than for the reduced-resolution period (Fig. 8).

It is difficult to draw final conclusions, because below $15 \mathrm{~km}$ only comparisons to ACE-FTS are available. They show that, similarly to $\mathrm{CH}_{4}$, it is likely that MIPAS reduced-
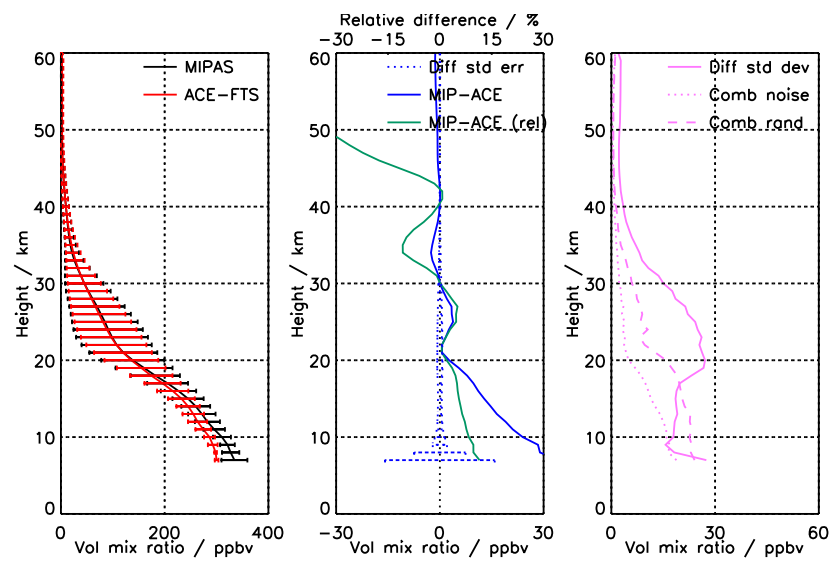

Figure 17. Comparison of $\mathrm{N}_{2} \mathrm{O}$ from ACE-FTS and MIPAS reduced resolution (V5R_N2O_224 and V5R_N2O_225) in 60$90^{\circ} \mathrm{N}$ in February and March. Details as in Fig. 1.

resolution spectra lead to higher mixing ratios than the fullresolution period data. Above $18 \mathrm{~km}$ the data from OdinSMR suggest that there is hardly any discrepancy between the MIPAS full- and reduced-resolution periods, while the differences to ACE-FTS do differ.

\section{Conclusions}

The new MIPAS-ENVISAT $\mathrm{CH}_{4}$ and $\mathrm{N}_{2} \mathrm{O}$ profiles versions V5H_CH4_21 and V5H_N2O_21 and V5R_CH4_224, V5R_CH4_225, V5R_N2O_224 and V5R_N2O_225 overall are found to have reduced the positive bias compared to other instruments. The bias for $\mathrm{CH}_{4}$ in the reduced-resolution period reported by Laeng et al. (2015) was reduced. The amount of this reduction is in the range of $0.08-0.15 \mathrm{ppmv}$. However it is likely that there still is a positive bias below $25 \mathrm{~km}$ for $\mathrm{CH}_{4}$ and $\mathrm{N}_{2} \mathrm{O}$. The remaining differences to the satellite instruments are between 0.1 and $0.2 \mathrm{ppmv}$ for $\mathrm{CH}_{4}$ and between 0.0 and $30 \mathrm{ppbv}$ for $\mathrm{N}_{2} \mathrm{O}$. The surface measurements also show slightly lower values than MIPAS. Since we would expect the surface mixing ratios to be higher due to the specific approach in our comparison method, this supports the findings of a high MIPAS bias in the inter-satellite comparisons at least in the upper troposphere. The two MIPAS measurement periods overall prove to be reasonably consistent. However, at least for $\mathrm{CH}_{4}$ it seems likely that the reduced-resolution period data have a slight positive bias of $0.05 \mathrm{ppmv}$ in the lower altitudes over the data from the fullresolution period. Due to the asymmetric nature of the MIPAS AKs for profile points below $12 \mathrm{~km}$, the application of the AKs to $\mathrm{N}_{2} \mathrm{O}$ profiles from a comparison instrument, in our case ACE-FTS, leads to rather large differences at the lower part of the profile and hence should not easily be dismissed. 
Acknowledgements. J. Plieninger was funded by the "Helmholtz Climate Initiative REKLIM" (Regional Climate Change), a joint research project of the Helmholtz Association of German research centres (HGF).

Work at the Jet Propulsion Laboratory, California Institute of Technology, was carried out under a contract with the National Aeronautics and Space Administration.

The Atmospheric Chemistry Experiment (ACE), also known as SCISAT, is a Canadian-led mission mainly supported by the Canadian Space Agency and the Natural Sciences and Engineering Research Council of Canada.

The article processing charges for this open-access publication were covered by a Research

Centre of the Helmholtz Association.

Edited by: K. Strong

\section{References}

Bernath, P. F., McElroy, C. T., Abrams, M. C., Boone, C. D., Butler, M., Camy-Peyret, C., Carleer, M., Clerbaux, C., Coheur, P.F., Colin, R., DeCola, P., De Mazière, M., Drummond, J. R., Dufour, D., Evans, W. F. J., Fast, H., Fussen, D., Gilbert, K., Jennings, D. E., Llewellyn, E. J., Lowe, R. P., Mahieu, E., McConnell, J. C., McHugh, M., McLeod, S. D., Michaud, R., Midwinter, C., Nassar, R., Nichitiu, F., Nowlan, C., Rinsland, C. P., Rochon, Y. J., Rowlands, N., Semeniuk, K., Simon, P., Skelton, R., Sloan, J. J., Soucy, M.-A., Strong, K., Tremblay, P., Turnbull, D., Walker, K. A., Walkty, I., Wardle, D. A., Wehrle, V., Zander, R., and Zou, J.: Atmospheric Chemistry Experiment (ACE): Mission overview, Geophys. Res. Lett., 32, L15S01, doi:10.1029/2005GL022386, 2005.

Boone, C. D., Nassar, R., Walker, K. A., Rochon, Y., McLeod, S. D., Rinsland, C. P., and Bernath, P. F.: Retrievals for the atmospheric chemistry experiment Fourier- transform spectrometer, Appl. Opt., 44, 7218-7231, 2005.

Boone, C. D., Walker, K. A., and Bernath, P. F.: Version 3 Retrievals for the Atmospheric Chemistry Experiment Fourier Transform Spectrometer (ACE-FTS), in: The Atmospheric Chemistry Experiment ACE at 10: A Solar Occultation Anthology, edited by Bernath, P. F., pp. 103-127, A. Deepak Publishing, Hampton, Virginia, USA, 2013.

Bovensmann, H., Burrows, J. P., Buchwitz, M., Frerick, J., Noël, S., Rozanov, V. V., Chance, K. V., and Goede, A. P. H.: SCIAMACHY: Mission objectives and measurement modes, J. Atmos. Sci., 56, 127-150, 1999.

De Mazière, M., Vigouroux, C., Bernath, P. F., Baron, P., Blumenstock, T., Boone, C., Brogniez, C., Catoire, V., Coffey, M., Duchatelet, P., Griffith, D., Hannigan, J., Kasai, Y., Kramer, I., Jones, N., Mahieu, E., Manney, G. L., Piccolo, C., Randall, C., Robert, C., Senten, C., Strong, K., Taylor, J., Tétard, C., Walker, K. A., and Wood, S.: Validation of ACE-FTS v2.2 methane profiles from the upper troposphere to the lower mesosphere, Atmos. Chem. Phys., 8, 2421-2435, doi:10.5194/acp-8-2421-2008, 2008.
Dlugokencky, E. J., Steele, L. P., Lang, P. M., and Masarie, K. A.: The growth rate and distribution of atmospheric methane, J. Geophys. Res., 99, 17021-17043, doi:10.1029/94JD01245, 1994.

Dlugokencky, E. J., Myers, R. C., Lang, P. M., Masarie, K. A., Crotwell, A. M., Thoning, K. W., Hall, B. D., Elkins, J. W., and Steele, L. P.: Conversion of NOAA atmospheric dry air $\mathrm{CH}_{4}$ mole fractions to a gravimetrically prepared standard scale, J. Geophys. Res., 110, D18306, doi:10.1029/2005JD006035, 2005.

Dlugokencky, E. J., Bruhwiler, L., White, J. W. C., Emmons, L. K., Novelli, P. C., Montzka, S. A., Masarie, K. A., Lang, P. M., Crotwell, A. M., Miller, J. B., and Gatti, L. V.: Observational constraints on recent increases in the atmospheric $\mathrm{CH}_{4}$ burden, Geophys. Res. Lett., 36, L18803, doi:10.1029/2009GL039780, 2009.

Dlugokencky, E. J., Lang, P. M., Crotwell, A. M., Masarie, K. A., and Crotwell, M. J.: Atmospheric Methane Dry Air Mole Fractions from the NOAA ESRL Carbon Cycle Cooperative Global Air Sampling Network, 1983-2014, available at: ftp://aftp.cmdl. noaa.gov/data/trace_gases/ch4/flask/surface/, last access: 3 August 2015.

Eckert, E., von Clarmann, T., Kiefer, M., Stiller, G. P., Lossow, S., Glatthor, N., Degenstein, D. A., Froidevaux, L., GodinBeekmann, S., Leblanc, T., McDermid, S., Pastel, M., Steinbrecht, W., Swart, D. P. J., Walker, K. A., and Bernath, P. F.: Drift-corrected trends and periodic variations in MIPAS IMK/IAA ozone measurements, Atmos. Chem. Phys., 14, 25712589, doi:10.5194/acp-14-2571-2014, 2014.

Elkins, J. W. and Dutton, G. S.: Nitrous oxide and sulfur hexafluoride [in "State of the Climate in 2008"], B. Am. Meteorol. Soc., 90, S38-S39, 2009.

Fischer, H., Birk, M., Blom, C., Carli, B., Carlotti, M., von Clarmann, T., Delbouille, L., Dudhia, A., Ehhalt, D., Endemann, M., Flaud, J. M., Gessner, R., Kleinert, A., Koopman, R., Langen, J., López-Puertas, M., Mosner, P., Nett, H., Oelhaf, H., Perron, G., Remedios, J., Ridolfi, M., Stiller, G., and Zander, R.: MIPAS: an instrument for atmospheric and climate research, Atmos. Chem. Phys., 8, 2151-2188, doi:10.5194/acp-8-2151-2008, 2008.

Glatthor, N., von Clarmann, T., Fischer, H., Funke, B., Grabowski, U., Höpfner, M., Kellmann, S., Kiefer, M., Linden, A., Milz, M., Steck, T., Stiller, G. P., Mengistu Tsidu, G., and Wang, D. Y.: Mixing processes during the Antarctic vortex split in September/October 2002 as inferred from source gas and ozone distributions from ENVISAT-MIPAS, J. Atmos. Sci., 62, 787-800, 2005.

Hall, B. D., Dutton, G. S., and Elkins, J. E.: The NOAA nitrous oxide standard scale for atmospheric observations, J. Geophys. Res., 112, D09305, doi:10.1029/2006JD007954, 2007.

Kiefer, M., Aubertin, G., Birk, M., De Laurentis, M., Eckert, E., Kleinert, A., Perron, G., and Wagner, G.: Impact of improved corrections for MIPAS detector non-linearity, in: Abstract Book, p. 38, talk: Atmospheric composition Validation and Evolution, Frascati, 13-15 March 2013, available at: http://congrexprojects.com/docs/default-source/acve_ docs/abstract-book-acve-for-the-web.pdf?sfvrsn=2 (last access: 18 November 2015), 2013.

Laeng, A., Plieninger, J., von Clarmann, T., Grabowski, U., Stiller, G., Eckert, E., Glatthor, N., Haenel, F., Kellmann, S., Kiefer, M., Linden, A., Lossow, S., Deaver, L., Engel, A., Hervig, M., Levin, I., McHugh, M., Noël, S., Toon, G., and Walker, K.: Validation 
of MIPAS IMK/IAA methane profiles, Atmos. Meas. Tech., 8, 5251-5261, doi:10.5194/amt-8-5251-2015, 2015.

Lambert, A., Read, W. G., Livesey, N. J., Santee, M. L., Manney, G. L., Froidevaux, L., Wu, D. L., Schwartz, M. J., Pumphrey, H. C., Jimenez, C., Nedoluha, G. E., Cofield, R. E., Cuddy, D. T., Daffer, W. H., Drouin, B. J., Fuller, R. A., Jarnot, R. F., Knosp, B. W., Pickett, H. M., Perun, V. S., Snyder, W. V., Stek, P. C., Thurstans, R. P., Wagner, P. A., Waters, J. W., Jucks, K. W., Toon, G. C., Stachnik, R. A., Bernath, P. F., Boone, C. D., Walker, K. A., Urban, J., Murtagh, D., Elkins, J. W., and Atlas, E.: Validation of the Aura Microwave Limb Sounder middle atmosphere water vapor and nitrous oxide measurements, J. Geophys. Res., 112, D24S36, doi:10.1029/2007JD008724, 2007.

Livesey, N. J., Read, W. G., Froidevaux, L., Lambert, A., Gloria, L. Manney, H. C. P., Santee, M. L., Schwartz, M. J., Wang, S., Richard, E. Cofield, D. T. C., Fuller, R. A., Jarnot, R. F., Jiang, J. H., Knosp, B. W., Paul, C. Stek, P. A. W., and Wu, D. L.: Earth Observing System (EOS), Aura Microwave Limb Sounder (MLS), Version 3.3 and 3.4 Level 2 data quality and description document, Tech. Rep. JPL D-33509, Jet Propulsion Laboratory, California Institute of Technology, Pasadena, CA, USA, available at: https://mls.jpl.nasa.gov/data/v3_data_quality_document. pdf (last access: 18 November 2015), 2013.

McHugh, M., Magill, B., Walker, K. A., Boone, C. D., Bernath, P. F., and Russell III, J. M.: Comparison of atmospheric retrievals from ACE and HALOE, Geophys. Res. Lett., 32, L15S10, doi:10.1029/2005GL022403, 2005.

Murtagh, D., Frisk, U., Merino, F., Ridal, M., Jonsson, A., Stegman, J., Witt, G., Eriksson, P., Jiménez, C., Megie, G., de la Nöe, J., Ricaud, P., Baron, P., Pardo, J. R., Hauchcorne, A., Llewellyn, E. J., Degenstein, D. A., Gattinger, R. L., Lloyd, N. D., Evans, W. F. J., McDade, I. C., Haley, C. S., Sioris, C., von Savigny, C., Solheim, B. H., McConnell, J. C., Strong, K., Richardson, E. H., Leppelmeier, G. W., Kyrölä, E., Auvinen, H., and Oikarinen, L.: An overview of the Odin atmospheric mission, Can. J. Phys., 80, 309-319, doi:10.1139/P01$157,2002$.

Noël, S., Bramstedt, K., Hilker, M., Liebing, P., Plieninger, J., Reuter, M., Rozanov, A., Bovensmann, H., and Burrows, J. P.: Stratospheric $\mathrm{CH}_{4}$ and $\mathrm{CO}_{2}$ profiles derived from SCIAMACHY solar occultation measurements, Atmos. Meas. Tech. Discuss., 8, 11467-11511, doi:10.5194/amtd-8-11467-2015, 2015.

Norton, H. and Beer, R.: New apodizing functions for Fourier spectrometry, J. Opt. Soc. Am, 66, 259-264, (Errata J. Opt. Soc. Am., 67, 419, 1977), 1976.

Plieninger, J., von Clarmann, T., Stiller, G. P., Grabowski, U., Glatthor, N., Kellmann, S., Linden, A., Haenel, F., Kiefer, M., Höpfner, M., Laeng, A., and Lossow, S.: Methane and nitrous oxide retrievals from MIPAS-ENVISAT, Atmos. Meas. Tech., 8, 4657-4670, doi:10.5194/amt-8-4657-2015, 2015.

Russell III, J. M., Gordley, L. L., Park, J. H., Drayson, S. R., Hesketh, W. D., Cicerone, R. J., Tuck, A. F., Frederick, J. E., Harries, J. E., and Crutzen, P. J.: The halogen occultation experiment, J. Geophys. Res., 98, 10777-10797, 1993.
Sheese, P. E., Boone, C. D., and Walker, K. A.: Detecting physically unrealistic outliers in ACE-FTS atmospheric measurements, Atmos. Meas. Tech., 8, 741-750, doi:10.5194/amt-8-7412015, 2015.

Urban, J., Lautié, N., Flochmoën, E. L., Jiménez, C., Eriksson, P., de La Noë, J., Dupuy, E., Ekström, M., El Amraoui, L., Frisk, U., Murtagh, D., Olberg, M., and Ricaud, P.: Odin/SMR limb observations of stratospheric trace gases: level 2 processing of $\mathrm{ClO}, \mathrm{N}_{2} \mathrm{O}, \mathrm{HNO}_{3}$, and $\mathrm{O}_{3}$, J. Geophys. Res., 110, D14307, doi:10.1029/2004JD005741, 2005.

von Clarmann, T.: Validation of remotely sensed profiles of atmospheric state variables: strategies and terminology, Atmos. Chem. Phys., 6, 4311-4320, doi:10.5194/acp-6-4311-2006, 2006.

von Clarmann, T., Glatthor, N., Grabowski, U., Höpfner, M., Kellmann, S., Kiefer, M., Linden, A., Mengistu Tsidu, G., Milz, M., Steck, T., Stiller, G. P., Wang, D. Y., Fischer, H., Funke, B., Gil-López, S., and López-Puertas, M.: Retrieval of temperature and tangent altitude pointing from limb emission spectra recorded from space by the Michelson Interferometer for Passive Atmospheric Sounding (MIPAS), J. Geophys. Res., 108, 4736, doi:10.1029/2003JD003602, 2003.

von Clarmann, T., Höpfner, M., Kellmann, S., Linden, A., Chauhan, S., Funke, B., Grabowski, U., Glatthor, N., Kiefer, M., Schieferdecker, T., Stiller, G. P., and Versick, S.: Retrieval of temperature, $\mathrm{H}_{2} \mathrm{O}, \mathrm{O}_{3}, \mathrm{HNO}_{3}, \mathrm{CH}_{4}, \mathrm{~N}_{2} \mathrm{O}, \mathrm{ClONO}_{2}$ and $\mathrm{ClO}$ from MIPAS reduced resolution nominal mode limb emission measurements, Atmos. Meas. Tech., 2, 159-175, doi:10.5194/amt-2-159-2009, 2009.

Waters, J. W., Froidevaux, L., Harwood, R. S., Jarnot, R. F., Pickett, H. M., Read, W. G., Siegel, P. H., Cofield, R. E., Filipiak, M. J., Flower, D. A., Holden, J. R., Lau, G. K., Livesey, N. J., Manney, G. L., Pumphrey, H. C., Santee, M. L., Wu, D. L., Cuddy, D. T., Lay, R. R., Loo, M. S., Perun, V. S., Schwartz, M. J., Stek, P. C., Thurstans, R. P., Boyles, M. A., Chandra, K. M., Chavez, M. C., Chen, G.-S., Chudasama, B. V., Dodge, R., Fuller, R. A., Girard, M. A., Jiang, J. H., Jiang, Y., Knosp, B. W., LaBelle, R. C., Lam, J. C., Lee, K. A., Miller, D., Oswald, J. E., Patel, N. C., Pukala, D. M., Quintero, O., Scaff, D. M., Snyder, W. V., Tope, M. C., Wagner, P. A., and Walch, M. J.: The Earth Observing System Microwave Limb Sounder (EOS MLS) on the Aura satellite, IEEE T. Geosci. Remote, 44, 1075-1092, doi:10.1109/tgrs.2006.873771, 2006.

Waymark, C., Walker, K. A., Boone, C. D., and Bernath, P. F.: ACEFTS version 3.0 data set: validation and data processing update, Ann. Geophys.-Italy, 56, 7 pp., doi:10.4401/ag-6339, 2013.

World Meteorological Organization (WMO): Meteorology - A Three-Dimensional Science: Second Session of the Commission for Aerology, WMO Bulletin, IV (4), 134-138, 1957. 